\title{
Inulina e Oligofrutoses: uma revisão sobre propriedades funcionais, efeito prebiótico e importância na indústria de alimentos
}

\author{
Inulin and Oligofructosis: a review about functional properties, \\ prebiotic effects and importance for food industry.
}

\author{
Maria Celia de Oliveira Hauly ${ }^{1}$; Janaína Andréa Moscatto ${ }^{2}$
}

\begin{abstract}
Resumo
Atualmente, os consumidores estão mais conscientes da relação que existe entre alimentação e saúde, de modo que, a indústria de alimentos tem procurado oferecer produtos que apresentem benefícios múltiplos, associados ao sabor e à aparência. Inulina e oligofrutoses são polímeros de frutose vastamente encontrados em plantas sob a forma de carboidratos de reserva, e apresentam propriedades funcionais de grande importância para a indústria de alimentos. Tanto inulina como oligofrutoses vêm sendo utilizadas para enriquecer com fibras produtos alimentares. Diferentemente de outras fibras, não têm sabores adicionais, podendo enriquecer os alimentos sem alterar muito a viscosidade, aparência e sabor das formulações. As propriedades nutricionais da inulina e oligofrutoses são similares, assim, a decisão de formular com inulina ou oligofrutoses se dá em função dos atributos desejados no produto final. A inulina é mais indicada quando se pretende obter produtos com menor teor de gordura (como sorvete, bolo e sopa), enquanto oligofrutoses são adequadas para iogurtes de baixa caloria, doçura e para mascarar o sabor residual de adoçantes de alta intensidade utilizados em preparações alimentares. Estudos têm indicado que inulina e oligofrutoses apresentam características de prebiótico, por serem indigeríveis e desenvolverem o efeito bifidogênico, melhorando a microbiota intestinal. Recomenda-se que inulina e oligofrutoses sejam utilizadas simultaneamente com probióticos em alimentos para obtenção do efeito simbiótico.
\end{abstract}

Palavras-chave : inulina; oligofrutoses; fibra alimentar; substituto de gordura; efeito prebiótico e simbiótico.

\begin{abstract}
Nowadays consumers are more conscious about the relation between food and health. Therefore food industry has been looking for food that has a lot of benefits besides good flavor and appearance. Inulin and oligofructose are fructose polimers, vastly found in plants as storage carbohydrates. They present important functional for the food industry. Both inulin and oligofructose have been used as fiber bulk in food products. Differently from other fibers, they do not add flavor, allowing the food to be improved without changing its viscosity. Inulin and oligofructose have similar nutritional properties. Inulin is more indicated for obtaining products with a low fat content such as ice cream, cake and soup, while oligofructose is indicated for yogurt with a low caloric value and in order to mask the residual flavor from high intensity sweeteners used in food preparation. Research has shown that inulin and oligofructose have prebiotic effects because they are not digestible and they can develop bifidogenic effects, improving the intestinal microflora. The simultaneous use of inulin and oligofructose with probiotic agents in food is recommended for symbiotic effects.
\end{abstract}

Key words: inulin; oligofructose; fiber; fat replacement; prebiotic effects and symbiotic effects.

${ }^{1}$ Docente do Departamento de Bioquímica/CCE/UEL e-mail mcoh@uel.br

${ }^{2}$ Aluna do Curso de Mestrado em Ciência e Tecnologia de Alimentos/CCA/TAM/UEL 


\section{Definição}

A inulina e as oligofrutoses, respectivamente, polímero e oligômeros de D-frutose, são importantes como carboidratos de reserva em plantas. Ambas pertencem ao grupo das frutanas e são sintetizadas por uma grande variedade de plantas (aproximadamente 36.000 espécies, que representam 10 famílias (CARPITA; KAMABUS; HOUSLEY,1989)).

As frutanas podem ser classificadas em: levanas, polímeros lineares com ligações tipo $\mathrm{b}(2 \rightarrow 6)$; compostos ramificados, polímeros que possuiem ligações tipo $b(2 \rightarrow 6)$ e $b(2 \rightarrow 1)$; e inulina, que é um polímero linear com ligações glicosídicas $\mathrm{b}(2 \rightarrow 1)$ (ROBERFROID, 1993). As estruturas das frutanas, inulina e levana, podem ser vistas na Figura 1.
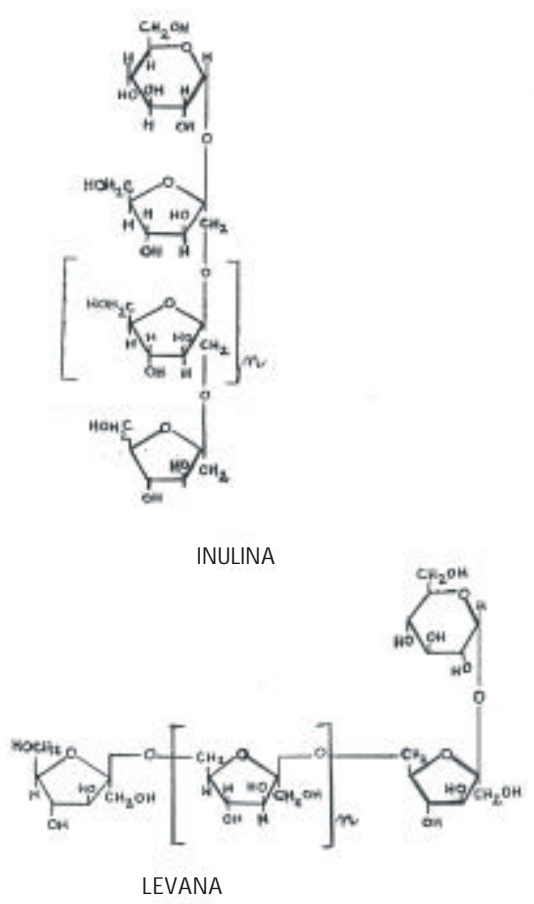

Figura 1: Estruturas de frutanas - inulina e levana

A inulina é uma frutana polidispersa, constituída de uma mistura de polímeros e oligômeros superiores lineares de frutose. As unidades de $\beta$-Dfrutofuranosil são mantidas entre si por ligações do tipo $\beta(2 \rightarrow 1)$, e possuem uma molécula de glicose na porção inicial de cada cadeia linear de frutose, a qual é unida por uma ligação tipo ( $\alpha 1-\beta 2)$, como na molécula de sacarose (QUEMENER; THIBAULT; COUSSEMENT, 1997; ROBERFROID, 1993).

O grau de polimerização destas cadeias (em média 30 unidades) pode alcançar 60 unidades de frutosila (DE LEENHEER; HOEBREGS, 1994; VAN HAASTRECHT, 1995; IUB-IUPAC, 1982).

A hidrólise (ácida ou enzimática) da inulina produz oligômeros lineares. Estes são estruturalmente designados GFn (glicose-frutose) (onde n representa o número de unidades frutofuranosil obtidas pela hidrólise), e Fm ,que é constituída apenas por frutose (onde $\mathrm{m}$ representa o número de unidades frutofuranosil obtidas). Os valores de $\mathrm{n}$ e $\mathrm{m}$ variam entre 2 e 9 (ROBERFROID, 1993; DE BRUYN et al., 1992). GFn e Fm têm propriedades físico-químicas muito semelhantes, embora se verifique a presença de grupo terminal frutose redutor, os produtos tipo Fm são redutores, enquanto os GFn são nãoredutores. Oligômeros de frutose são denominados de fruto-açúcar, frutooligossacarídeos (FOS) ou, de forma simplificada, oligofrutoses (ROBERFROID, 1993).

De acordo com a terminologia da IUB-IUPAC (1982), o ponto de divisão entre oligo e polissacarídeos é 10, não havendo razão fisiológica ou química para esta divisão. Portanto, na prática, a nomenclatura para oligossacarídeos é empírica.

Embora as formas mais comuns de polifrutose empregadas sejam a inulina como tal ou sob a forma de oligômeros que menor grau de polimerização, o polímero pode ser igualmente convertido a uma forma desidratada de inulobiose (designada DFA III) ou à difrutose anidrido, que também apresenta propriedades interessantes para exploração comercial (HAULY et al., 1992; FONTANA et al., 1994a ). 


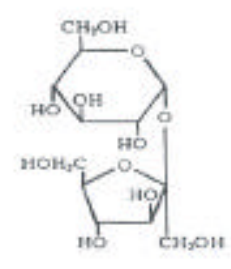

GF

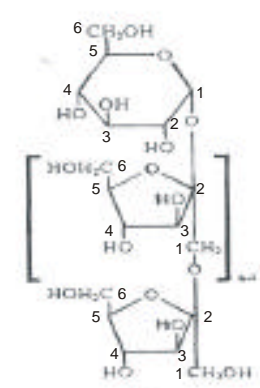

C.F.

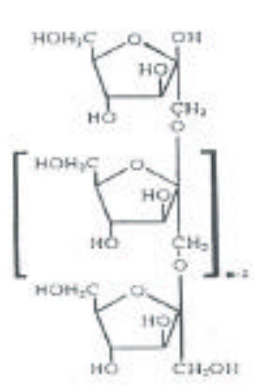

$F_{r}$
Figura 2 - Estrutura molecular da sacarose (esquerda), inulina (centro) e oligofrutose (centro e direita), onde $\mathrm{G}=$ glicose e $\mathrm{F}=$ frutose.

\section{Ocorrência Natural}

A inulina é um carboidrato largamente encontrado na natureza, funcionando como carboidrato de reserva em muitas plantas. As plantas apresentam hidrólise da inulina endógena em moléculas de menor grau de polimerização, o que permite a sobrevivência destas plantas durante o inverno em regiões frias e moderadamente frias, e atua na osmorregulação (CARPITA; KAMABUS; HOUSLEY, 1989).

Muitas plantas que contêm inulina fazem parte da dieta humana básica há muito tempo, sendo a cebola a mais consumida entre elas. A concentração de inulina em cada planta depende muito da variedade, do tempo decorrido desde a colheita até a utilização desta e das condições de estocagem. Na cebola, dependendo destes fatores, a concentração de inulina pode chegar a até $50 \%$ da matéria seca (RUTHERFORD; WHITTLE, 1982; SUZUKI; CUTCLIFE, 1989).

Outros vegetais, do mesmo gênero da cebola, que contêm inulina são alho-porró e alho, os quais apresentam, respectivamente, $18-60 \%$ e $22-40 \%$, da matéria seca em inulina (ASAMI et al.,1989).

Existem ainda outros vegetais que contêm consideráveis concentrações de inulina e são bastante consumidos. entre eles, salientam-se o aspargo que contém ,em base seca ,cerca de $30 \%$ de inulina nas raízes (FIALA; JOLIVET, 1982); a alcachofra apresenta 65\% em inulina (OKEY; WILLIAMS, 1920); a barba de bode, com mais de $50 \%$ da matéria seca é INULINA (VAN REE, 1982); e as raízes tuberosas de dália, que fornecem, em base seca, um rendimento de 50\% de inulina (HAULY,1991).

Além dos vegetais, muitos cereais também contêm inulina. Entre eles estão o trigo, a cevada, o centeio, com concentrações variando entre 1-4\% (NILSSON; DAHLQUIST, 1986).

Para a maioria das fontes (alho, cebola, aspargo), as concentrações de inulina e oligofrutoses estão entre 0,3 a $6 \%$ do peso fresco, podendo chegar a $10 \%$ para a barba de bode. Entretanto, para alcachofra de Jerusalém, chicória, dália e yacon as concentrações de inulina e oligofrutoses podem chegar até $20 \%$ do peso fresco, fazendo destes vegetais importantes fontes de inulina e oligofrutoses (VORAGEN, 1998).

Tabela 1: Inulina e oligofrutose (\% do peso fresco) em plantas utilizadas na alimentação humana

\begin{tabular}{lccc}
\hline Plantas & Parte Comestível & Inulina & Oligofrutose \\
\hline Cebola & Bulbo & $2-6$ & $2-6$ \\
Alcachofra Jerusalém & Tubérculo & $16-20$ & $10-15$ \\
Chicória & Raiz & $15-20$ & $5-10$ \\
Alho-porró & Bulbo & $3-10$ & $2-5$ \\
Alho & Bulbo & $9-16$ & $3-6$ \\
Alcachofra & Folhas centrais & $3-10$ & $<1$ \\
Banana & Fruta & $0,3-0,7$ & $0,3-0,7$ \\
Centeio & Cereal & $0,5-1$ & $0,5-1$ \\
Cevada & Cereal & $0,5-1,5$ & $0,5-1,5$ \\
Dente de leão & Folhas & $12-15$ & NA \\
Yacon & Raiz & $3-19$ & $3-19$ \\
Barba de bode & Folhas & $4-11$ & $4-11$ \\
Trigo & Cereal & $1-4$ & $1-4$
\end{tabular}

Fonte: Van Loo et al.1995, Moshfegh et al.1999.

\section{Determinação Analítica}

A inulina e as oligofrutoses podem ser analisadas utilizando o Método de Frutana descrito pela AOAC (Association of Official Analytical Chemists) número 997.08 e integrada ao Método de Fibra Dietética Total da AOAC (QUEMENER; THIBAULT; COUSSEMENT, 1994, 1997; HOEBREGS, 1997; SIMONOVSKA, 2000). Esse método mede a inulina total mais as oligofrutoses em qualquer produto alimentar, sendo um método bastante específico para ambas as substâncias e tendo se mostrado reprodutível. As oligofrutoses podem ainda ser determinadas usando 
CLAE (cromatografia líquida de alta eficiência) ou GLC (cromatografia líquida gasosa) (VAN LOO et al.,1995).

\section{Propriedades Funcionais e Aplicações Tecnológicas}

A inulina extraída de plantas, após a secagem, apresenta-se como um pó branco, amorfo, higroscópico, com odor e sabor neutros, tem densidade de aproximadamente 1,35 e peso molecular de 1600 .

A solubilidade da inulina varia em função da temperatura da água. A solubilidade é de aproximadamente $6 \%$ a $10^{\circ} \mathrm{C}$, enquanto que a $90^{\circ} \mathrm{C}$ é de $35 \%$, o que dificulta seu emprego à temperatura ambiente. A inclusão de resíduos ainda que lipofílicos, altera esta situação e tais derivados têm demonstrado capacidade de induzir enzimas desfragmentadoras de inulina ou seja, as inulinases (FONTANA et al., 1994b).

A inulina tem uma capacidade de ligação de água de 2:1, ou seja, duas moléculas de água para cada molécula de inulina. Em solução, a inulina reduz o ponto de congelamento da água e aumenta o ponto de fusão (SILVA, 1996).

A funcionalidade da inulina está baseada em seu efeito sobre soluções aquosas a vários níveis de sólidos. À medida que a concentração de inulina aumenta, a viscosidade aumenta gradativamente .

Para formar gel, a inulina tem que estar numa concentração em que se apresente em discretas partículas. Assim, quando o nível de inulina alcança 30\% de sólidos em solução aquosa, a combinação inulina - água inicia a gelificação. Neste nível, o gel é formado sob resfriamento por 30 a 60 minutos. Quando o nível de inulina aumenta, o gel precisa de menos tempo para ser formado, sendo praticamente instantâneo quando o nível de sólidos em solução está entre $40-45 \%$.

O gel de inulina é muito cremoso e assemelha-se à textura da gordura ao toque e sua força depende principalmente da concentração de inulina entre outros fatores (GRUHN, 1994).
A disponibilidade de água é o fator que mais afeta as características do gel. Entretanto, o tamanho da cadeia de inulina (grau de polimerização); concentrações de mono e dissacarídeos presentes; tamanho das partículas de inulina; método de preparação; temperatura; adição de outros hidrocolóides e cátions mono e divalentes também podem afetar o gel (SILVA, 1996).

As diferenças no tamanho das cadeias entre inulina e oligofrutoses, causam diferenças também nos atributos funcionais tecnológicos destes compostos.

Devido ao fato de apresentar cadeia maior, a inulina é menos solúvel que a oligofrutoses e tem a habilidade de formar microcristais de inulina quando misturada em água ou leite. Estes microcristais não são percebidos na boca, mas interagem para formar uma textura finamente cremosa que promovem na boca uma sensação semelhante ao da gordura. Inulina tem sido usada com sucesso como substituto de gordura em vários produtos alimentares como bolos, chocolates, embutidos, produtos lácteos (NINESS, 1999).

As oligofrutoses ou frutooligossacarídeos (FOS) constituem-se de cadeias menores e possuem qualidades funcionais similares aos xaropes de sacarose ou glicose. São mais solúveis que a sacarose e fornecem entre $30-50 \%$ da doçura desta. As oligofrutoses contribuem para encorpar produtos lácteos e melhorar a umectância de produtos de panificação, diminuir o ponto de congelamento de sobremesas congeladas, fornecer crocância a biscoitos de baixo teor de gordura, e agir como um aglutinante em barras nutricionais de granola. Desse modo, elas exercem o mesmo papel que a sacarose, mas têm as vantagens de apresentar menor valor calórico, enriquecer o teor de fibras e outras propriedade nutricionais em alimentos. Adicionalmente, é utilizada em combinação com adoçantes de alta intensidade em substituição a sacarose, fornecendo um perfil de doçura bem balanceado e mascarando o sabor residual de aspartame (WEIDMANN; JAGER, 1997). 
A inulina e as oligofrutoses são utilizadas para enriquecer com fibras produtos alimentares. Diferentemente de outras fibras, não têm sabores adicionais, e podem enriquecer os alimentos sem contribuir muito com a viscosidade. Estas propriedades permitem a formulação de alimentos com alto teor de fibras mantendo a aparência e o gosto das formulações padrões.

As oligofrutoses são comumente utilizadas em cereais, preparações de frutas para iogurtes, sobremesas congeladas, cookies e produtos lácteos nutricionais.

As propriedades nutricionais da inulina e oligofrutoses são similares, assim a decisão de formular com inulina ou oligofrutoses se dá em função dos atributos desejados no produto final.

Sendo assim, a inulina é mais comumente usada quando se pretende obter produtos com menor teor de gordura, enquanto que as oligofrutoses são mais adequadas para as preparações de frutas para iogurtes de baixa caloria e para balancear a doçura e mascarar o sabor residual de adoçantes de alta intensidade utilizados em preparações alimentares (NINESS, 1999).

A inulina e as oligofrutoses têm sido usadas em muitos países para substituir gordura ou açúcar e reduzir as calorias de alimentos tais como sorvete, produtos lácteos, confeitos e produtos de panificação. Contudo, é a indigeribilidade da inulina e das oligofrutoses que tem permitido a maior utilização destas como fibra alimentar.

As fibras alimentares foram definidas pela AOAC como "resíduos de células vegetais resistentes a hidrólise pelas enzimas alimentares humanas" (TROWEL; BURKITT, 1986).

No Brasil, o Ministério da Saúde, através da portaria n. ${ }^{\circ} 41$, de 14/01/1988 definiu Fibras Alimentares como "qualquer material comestível de origem vegetal que não seja hidrolisado pelas enzimas endógenas do trato digestivo humano, determinado segundo o método enzimático gravimétrico 985.19 da AOAC, 15 a edição, 1990 ou edição mais atual" (SÁ; FRANCISCO, 1999).

Lee e Prosky (1995) ampliariam a definição de fibra alimentar, especialmente incluindo oligossacarídeos indigeríveis. Inulina e oligofrutoses enquadram-se nessa definição e são medidas analiticamente com o uso do Método de Frutana AOAC 977.08, recentemente aprovado (HOEBREGS, 1997).

A definição fisiológica de fibra alimentar relaciona-a a uma melhora da função intestinal. Embora não haja uma lista oficial das funções fisiológicas que a fibra deve possuir para se enquadrar nesta definição, geralmente os efeitos fisiológicos aceitos de fibra incluem, além de um efeito sobre a função intestinal, a melhora de parâmetros lipídicos sangüíneos. As fibras alimentares também apresentam um valor calórico reduzido (ROBERFROID, 1993).

Segundo Ellegard, Anderson, Bosaeus (1997) e Knudsen e Hessov (1995) quase toda a inulina e as oligofrutoses ingeridas são fermentadas pela microbiota intestinal, sendo convertidas em ácidos graxos de cadeia curta (acetato, propionato e butirato) , lactato, biomassa bacteriana e gases. Somente o metabolismo dos ácidos graxos de cadeia curta e do lactato contribuem para o metabolismo energético do hospedeiro.

As perdas calóricas devem-se ao fato de parte da energia ser usada para a síntese de biomassa microbiana e uso produz gases como hidrogênio, metano e dióxido de carbono. Somente uma fração do valor da energia original é conservada nos ácidos graxos de cadeia curta, mas ainda assim, tecidos do hospedeiro usam somente parte da energia dos ácidos graxos de cadeia curta, e alguns dos ácidos graxos de cadeia curta são excretados. Entretanto, o lactato é largamente absorvido e pode ser uma fonte de energia para as próprias bactérias (ZIESENITZ; SIEBERT, 1987; BERNIER; PASCAL, 1990; ROBERFROID,1993). 
O valor calórico das substâncias obtidas da fermentação da inulina e oligofrutoses foi estimado em 1-3 Kcal/g (BERNIER; PASCAL, 1990).

Segundo Roberfroid (1993) quando a frutose está ligada, como nas oligofrutoses, $40 \%$ são convertidos em biomassa bacteriana, $5 \%$ em $\mathrm{CO}_{2}, 40 \%$ em ácidos graxos de cadeia curta e $15 \%$ em lactato, e somente $90 \%$ destes metabólitos são absorvidos no sangue. O metabolismo destes compostos no fígado produz 14 mols de ATP, que é 35\% do conteúdo calórico da frutose livre. Isto conduz a um valor calórico de 1,4 Kcal/g de oligofrutoses.

A inulina e as oligofrutoses influenciam a função intestinal pelo aumento da frequiência das evacuações, particularmente em pacientes constipados (GIBSON et al., 1995, HIDAKA et al., 1986; MENNE et al.,1997). O aumento do peso das fezes nas evacuações, (cerca de $2 \mathrm{~g}$ por $\mathrm{g}$ de inulina ou oligofrutoses ingeridas (GIBSON et al.,1995, OKU; TOKUNAGA, 1984)) e a diminuição do pH fecal devido à fermentação (GIBSON; ROBERFROID, 1995; MENNE et al., 1997), têm sido relacionados à supressão da produção de substâncias putrefativas no cólon.

Adicionalmente, observa-se uma diminuição dos triacilgliceróis e níveis de colesterol plasmáticos em pacientes hipercolesterolêmicos. Estes efeitos são relacionados a uma atividade reduzida das enzimas lipogênicas hepáticas (BRIGHENTI et al., 1995; FIORDALISO et al. 1995; HATA et al. 1983; HIDAKA et al. 1986; KOK et al. 1996; SANNO, 1986 ; YAMASHITA; KANAI; ITAKUCA, 1984).

Sendo a inulina e oligofrutoses resistentes à digestão na porção superior do trato intestinal (KNUDSEN; HESSOV, 1995), ambas alcançam o intestino grosso praticamente intactas, onde são fermentadas pelas bactérias, podem então ser classificadas como fibras alimentares solúveis (ROBERFROID, 1993). Portanto, do ponto de vista analítico e fisiológico, a inulina e as oligofrutoses deveriam ser classificadas como fibras alimentares (GRAHAM; ANAN, 1986; KNUDSEN; HESSOV,
1995; LEE; PROSKY, 1995; NILSSON et al., 1988, ROBERFROID, 1993).

A evidência da relação entre fibra alimentar e doença cardiovascular aterosclerótica é muito forte. Ela surgiu a partir de estudos em animais (PILCH, 1987), observações epidemiológicas (RIMM et al., 1996) e de um número limitado de ensaios clínicos (ANDERSON, 1995a). TROWEL (1972) também estudou essa relação e concluiu que uma dieta deficiente em fibra poderia contribuir para uma maior incidência de doenças coronárias.

As fibras alimentares, especialmente as solúveis ou viscosas, efetivamente diminuem o colesterol sérico e as concentrações do colesterol LDL, que tem papel central na patogênese da aterosclerose, podendo contribuir na proteção contra doenças coronárias (ANDERSON, 1990).

Os efeitos das fibras solúveis ou viscosas na diminuição do colesterol estão relacionadas com suas propriedades de formação de gel (ANDERSON, 1995b), a diminuição da absorção de ácidos biliares e a ação dos ácidos graxos de cadeia curta produzidos na fermentação sobre a função hepática (ANDERSON, 1995c; ANDERSON; CHEN, 1979; WRIGHT, ANDERSON, BRIDGES, 1990). Além disso, verifica-se que as fibras podem também atuar sobre fatores de risco para doenças coronárias como hipertensão, obesidade e diabetes (ASCHERIO et al., 1992; MANSON et al., 1995; ANDERSON, 1995b).

Reduções drásticas dos triacilgliceróis séricos têm sido observadas em ratos que consomem relativamente maiores doses de oligofrutoses, embora reduções no colesterol só tenham sido observadas com alimentação destes com oligofrutoses por longo tempo (DELZENNE et al., 1993; FIORDALISO et al., 1995). Embora os dados obtidos de estudos com animais sugiram convincentes propriedades redutoras de lipídios por oligofrutoses e inulina, poucas informações de estudos com humanos são evidentes, pois as doses que podem ser aplicadas em seres humanos são muito menores que aquelas que tem sido usadas para obtenção de efeitos em animais (WILLIAMS, 1999). 
Estudos com voluntários humanos indicam que inulina e oligofrutoses têm um efeito modulatório nos parâmetros lipídicos. Foi relatado que o consumo de frutanas reduz triacilgliceróis e colesterol séricos, principalmente LDL, em voluntários hiperlipidêmicos. Entretanto, parâmetros lipídicos de adultos normais não foram afetados (DAVIDSON et al. 1998).

Hata et al. (1983) estudaram durante 4 semanas o efeito do consumo de $13 \mathrm{~g} /$ dia de oligofrutoses em 46 pacientes com hiperlipidemia. Foi observada uma diminuição significativa no colesterol sérico total e na pressão sangüínea e uma discreta diminuição no peso corporal, glicemia, triacilgliceróis e ácidos graxos livres.

Segundo Van Loo et al. (1999) apesar das informações obtidas até o momento ainda serem consideradas inconsistentes, pode-se afirmar o consumo de inulina e de oligofrutoses podem afetar o metabolismo lipídico humano no sentido de diminuir o colesterol total.

Em adição aos benefícios para o metabolismo lipídico, a influência protetora e inibitória da inulina e oligofrutoses no desenvolvimento do câncer e crescimento de tumor que vem sendo muito discutido (MILNER, 1994; ROBERFROID, 1991; WILLIAMS; DICKERSON, 1990).

A inulina e as oligofrutoses estimulam seletivamente o crescimento de bifidobactérias e mantêm em níveis baixos os Bacteroides, Clostridia ou coliformes contribuindo na prevenção de câncer de cólon (GIBSON; ROBERFROID, 1995; GIBSON et al.,1995). Gibson et al. (1995) demonstraram que a administração de inulina e oligofrutoses aumenta significativamente as bifidobactérias fecais, produtodes do ácido lático, diminuindo o $\mathrm{pH}$ fecal e criando um microambiente bactericida para bactérias putrefativas, desenvolvendo assim, um microambiente favorável. Este microambiente pode envolver também a modulação de enzimas bacterianas como b-glicuronidase que pode converter procarcinógenos em carcinógenos (KULKARNI; REDDY, 1994).
Cooper e Carter (1986) demonstraram a atividade imuno-estimulante de inulina em ratos. A ingestão desta resultou em um aumento na produção de macrófagos que matam células cancerosas .

Roland et al. (1994a; 1994b; 1995; 1996) demonstraram uma capacidade aumentada de detoxificação do fígado (citocromo P450) em ratos alimentados com inulina. A produção de glutation-S-transferase e glucoroniltransferase foi aumentada. Estas enzimas metabolizadoras de xenobióticos podem exercer um papel importante contra produtos carcinogênicos.

Em experimentos preliminares Taper e Roberfroid (1999) observaram que a incidência de tumor (carcinogênese mamária) foi menor no grupo de ratos que foram alimentados com $15 \%$ de oligofrutoses. O número de tumores durante o período de carcinogênese foi também significativamente menor no grupo alimentado com oligofrutoses, quando comparado ao grupo controle alimentado com amido.

Embora os prováveis mecanismos pelos quais as oligofrutoses e a inulina inibem as lesões préneoplásicas do cólon não sejam completamente entendidos, sugere-se que os efeitos destes agentes podem envolver a modulação da microbiota no cólon (GIBSON; ROBERFROID, 1995; GIBSON et al., 1995).

Segundo Karppinen et al. (2000) e Gibson e Roberfroid (1995), a fermentação da inulina é mais rápida e produz relativamente mais ácido butírico e menos ácido propriônico que os farelos de cereais. Este butirato é capaz de inibir a proliferação de um grande número de células in "vitro", inclusive de células tumorais (GAMET et al. 1992).

Embora a atuação do butirato não seja o único mecanismo pelo qual oligofrutoses e inulina podem inibir o câncer de cólon, ele pode explicar em parte porque estes agentes parecem ser protetores (REDDY, 1999). Hughes e Rowland (2001) mostraram que apoptose foi significativamente maior no cólon de ratos alimentados com inulina e oligofrutoses quando comparado com o grupo padrão alimentado com dieta basal. Sabe-se que fato- 
res que aumentam a apoptose podem reduzir as chances de formação de tumor no cólon.

Efeitos adicionais à saúde, devidos ao aumento da absorção de minerais, principalmente o cálcio, também estão sendo relacionados ao consumo de inulina e oligofrutoses (DELZENNE et al. 1995, OHTA et al. 1994). A ingestão freqüente de inulina ou oligofrutoses diminuem ou previnem a perda de massa óssea, cálcio e fósforo dos ossos de ratos gastrectomizados (OHTA et al. 1998) e a perda de densidade mineral óssea por ratos ovarioctomizados (TAGUCHI et al. 1994).

O aumento da absorção de minerais em ratos alimentados com estes carboidratos foi associado à diminuição do $\mathrm{pH}$ do íleo e cécon, hipertrofia das paredes do cécon e aumento nas concentrações de ácidos graxos voláteis, ácidos biliares, cálcio, fosfato e diminuição no magnésio, no conteúdo cecal (LEVRAT, RENESY, DEMIIGNÉ, 1991; OHTA et al., 1994).

Segundo Lopez et al. (2000) a fermentação dos frutooligossacarídeos pode estimular a absorção mineral na porção distal do trato digestivo de ratos através de diminuição do $\mathrm{pH}$; massa mucosa aumentada e hidrólise bacteriana do ácido fítico, cuja presença em planta diminui a absorção de minerais.

Van Den Heuvel et al. (1998) não observaram efeito na absorção de cálcio e ferro em humanos adultos após a ingestão de inulina e oligofrutoses. Entretanto, observaram um aumento na absorção de cálcio em adolescentes após a ingestão de oligofrutoses (VAN DEN HEUVEL et al., 1999). Em adição, Coudray et al. (1997) notaram que inulina aumentou a absorção de cálcio, mas não a absorção de magnésio, ferro e zinco em humanos.

Segundo Lopez et al.(2000) trabalhos futuros são ainda necessários para a validação dos resultados obtidos até agora com relação à absorção de minerais.

\section{Efeito Prebiótico}

Segundo Gibson e Roberfroid (1995), prebiótico é um ingrediente alimentar indigerível que afeta beneficamente o hospedeiro por estímulo seletivo do crescimento e atividade de um ou um número limitado de bactérias no cólon, o que pode então melhorar a saúde do hospedeiro.

Alguns dos critérios que permitem a classificação de um ingrediente como um prebiótico, são: ele não deve ser hidrolisado, nem absorvido na porção superior do trato gastrointestinal; deve ser seletivamente fermentado por um ou um número limitado de bactérias potencialmente benéficas no cólon; deve alterar a composição da microbiota colonizadora para uma composição mais saudável; deve induzir preferencialmente efeitos que sejam benéficos para a saúde do hospedeiro.

Estudos"in vitro"têm indicado que a inulina e as oligofrutoses apresentam as características de prebiótico desenvolvendo fermentação específica e melhorando a microbiota intestinal (HIDAKA et al.,1986, WANG; GIBSON, 1993). Isso também tem sido confirmado em ensaios com voluntários humanos, que apresentaram efeitos bifidogênicos para inulina e oligofrutoses "in vivo" (GIBSON, 1999; BUDDINGTON et al., 1996; KLEESEN et al., 1997). Outras investigações têm confirmado o efeito prebiótico da inulina e oligofrutoses "in vivo" (BUDDINGTON et al.,1996; KLEESEN et al.,1997). Roberfroid, Van Loo, Gibson (1998) compilaram todos os possíveis dados relatando o efeito bifidogênico da inulina e das oligofrutoses de chicória. Eles demonstraram que o efeito destas independe do tamanho da cadeia polimérica e se são do tipo GFn ou Fm.

As funções do intestino humano incluem absorção de água, certos minerais, o armazenamento e excreção de resíduos materiais. Entretanto, devido à microbiota residente, o cólon tem um papel importante na nutrição e possivelmente, na saúde humana (GIBSON; MACFARLANE, 1995). 
As bactérias intestinais são capazes de metabolizar substratos para aumentar a energia e o crescimento. Os principais produtos finais do metabolismo são ácidos os graxos de cadeia curta (acetato, propionato e butirato), mas uma variedade de outros metabólitos também são produzidos como lactato, piruvato, etanol, hidrogênio e succinato. Essas substâncias são formadas para a manutenção do balanço redox durante a fermentação.

Sob condições de homeostase, a microbiota intestinal é de vital importância para a prevenção da colonização do intestino por patógenos. Ela também apresenta muitos benefícios locais e sistêmicos como aumento da tolerância a lactose, propriedades antitumorais, neutralização de certas toxinas, estímulo do sistema imune intestinal e possivelmente, redução dos níveis lipídicos no sangue (FULLER, 1989, 1992, 1997; ISOLAURI et al.,1991; KOHWI et al., 1978; LIN et al.,1989; SANDERS, 1994).

A inulina e as oligofrutoses são utilizadas também simultaneamente com probióticos. Os probióticos são suplementos alimentares microbianos que beneficiam o hospedeiro pela melhoria do balanço da microbiota intestinal, por meio do consumo de alementos que permitem obter efeitos sinérgicos. Isso ocorre porque, em adição à ação de prebióticos que promovem o crescimento de linhagens existentes de bactérias benéficas no cólon, a inulina e as oligofrutoses também promovem a sobrevivência, implantação e crescimento de novas linhagens probióticas adicionadas, criando, assim, o efeito simbiótico (COUSSEMENT, 1997). Probióticos comuns incluem: lactobacilos, cocos Gram positivos e bifidobactérias como B.bifidum, B.adolescentis, B.animales, B.infantes, B.longum, B.thermophilun (FULLER,1992).

Em termos de mecanismos de inibição, produtos metabólicos finais, como os ácidos excretados por estes microrganismos, podem diminuir o $\mathrm{pH}$ intestinal a níveis abaixo dos quais patógenos são capazes de competir efetivamente. $\mathrm{O}$ aumento da função imunológica pode também ser um fator importante.

Muitas espécies de lactobacilos e bifidobactérias são capazes de excretar antibióticos naturais como lactocinas, lactacinas, curvacinas, bifidocinas, as quais podem ter um amplo espectro de atividade. Para as bifidobactérias, estudos têm indicado que algumas espécies têm atividade antimicrobiana atuam sobre vários patógenos intestinais, Gram positivos e Gram negativos, incluindo Salmonella, Campylobacter e Escherichia coli (GIBSON; WANG, 1994).

Outros benefícios para a saúde associados às bifidobatérias são estimulação de componentes do sistema imune, ajuda na absorção de certos íons e na síntese de vitaminas do complexo B (GIBSON, 1999).

\section{Toxicidade}

Numerosas publicações documentam estudos realizados com bastante rigor e controle, desenvolvidos com inulina e oligofrutoses em pessoas normais e doentes. Estudos com indivíduos de diferentes idades têm fornecido resultados que garantem a inocuidade da inulina e oligofrutoses (ROBERFROID, 1993).

A inulina tem sido usada para avaliar a taxa de filtração glomerular por injeção intravenosa desde 1931. Isto tornou-se um procedimento padrão sem efeitos tóxicos (PRICE, SCWARTZ, HOYT, 1978). Adicionalmente, a história de uso de alimentos contendo inulina pelo homem não mostrou evidência de efeitos tóxicos (COUSSEMENT, 1999).

Um comitê de especialistas, baseado em uma revisão destes estudos, concluiu que não há razão para admitir-se a inulina ou as oligofrutoses e seus metabólitos possam ter efeitos tóxicos pelo uso de alimentos. Ao contrário, estudos recentes documentam efeitos nutricionais benéficos destas no trato gastrointestinal do homem (KOLBYE et al.,1992). 
Hauly, M. C. de O . et al

\section{Inulina e Oligofrutoses na Indústria de Ali- mentos}

Atualmente os consumidores têm exigido altos padrões para os alimentos.Os alimentos devem apresentar sabor agradável, baixo valor calórico ou baixo conteúdo em gorduras, apresentar benefícios adicionais à saúde. Os consumidores estão mais bem informados e conscientes da relação que existe entre alimentação e saúde. Logo, estão procurando por alimentos que apresentem benefícios múltiplos associados a sabor e aparência.

Doenças do coração, câncer, estresse, colesterol alto, controle de peso, osteoporose e diabetes são, atualmente, as maiores preocupações de saúde. Sendo assim, o foco na prevenção de doenças por meio dos alimentos está muito forte. Isso faz com que a inulina e as oligofrutoses apareçam como importantes ingredientes alimentares que podem ser largamente explorados pela indústria de alimentos, visando à produção de alimentos funcionais (NINESS, 1999).

\section{Referências Bibliográficas}

ANDERSON, J. W.; CHEN, W. L. Plant fiber: carbohydrate and lipid metabolism Am. J. Clin. Nutr. v.32, p.346-363, 1979.

ANDERSON, J. W. Cholesterol - lowering effects of soluble fiber in human. In: KRITCHEVSKY, D.; BONFIELD, C. (Eds.). Dietary Fiber in Healthy and Disease. St. Paul: Eagar Press, 1995b. p.126-145.

ANDERSON, J. W. Dietary fiber and human healthy. Hortc. Sci. v.25, p.1488-1495, 1990.

ANDERSON, J. W. Dietary fibre, complex carbohydrate and coronary heart disease. Can. J. Cardiol. v.11, p.55G$62 \mathrm{G}, 1995 \mathrm{a}$.

ANDERSON, J. W. Short chain fatty acids in lipid metabolism: human studies. In: Cummings, J. H.; Rombeau, J. L.\& Sakata, T.; (Eds.)Physiological and Clinical Aspects of Short Chain Fatty Acids, , New York: Cambridge University Press, 1995c. p. 509-523.

ASAMI, T. et al. Chemical composition of yacon, a new root crop from the Andean Highlands. Jpn. J. Soil Sci. Plant Nutr., v.60, p.122-126, 1989.
ASCHERIO, A. et al. A prospective study of nutritional factors and hypertension among US men. Circulation, v.86, p.1475-1484, 1992.

BERNIER, J. J.; PASCAL, G. Valuer energétique des polyols (sucres-alcools). Med. Et Nut. v.26, p.231-238, 1990.

BRIGHENTI, F. et al. One month comsuption of readyto-eat breakfast cereal containing inulin markedly lowers serum lipids in normolipidemic men. In: EUROPEAN NUTRITION CONFERENCE, 7., 1995, Vienna.

BUDDINGTON, R. K. et al. Dietary supplementation of neosugar alters the fecal flora and decreases activities of some reductive enzymes in human subjects. Am. $J$. Clin. Nutr., v.63, p.709-716, 1996.

CARPITA, N. C.; KAMABUS, J.; HOUSLEY, T. L. Linkage structure of fructans and fructan oligomers from Triticum astivum and Fistuca arundinaceae leaveas. $J$. Plant. Physiol., v.134, p.162-168, 1989.

COOPER, P. D.; CARTER, M. The anti-melanoma activity of inulin in mice. Mol. Immunol., 23, p.903-908, 1986.

COUDRAY, C. et al. Effect of soluble or partly soluble dietary fibres supplementation on absorption and balance of calciun, magnesiun, iron and zinc in healthy young men. Eur. J. Clin. Nutr., 51, p.375-380, 1997.

COUSSEMENT, P. Powerful products. The World of Ingredients, v.7, p.12-17, aug., 1997.

COUSSEMENT, P. A. Inulin and oligofructose: safe intakes and legal status. J. Nutr. v.129, suppl., p.14121417, 1999.

DE BRUYN, A. et al. Isolation and identification of b-D fructofuranosyl - (2 ®1) - b-D frustofuranosyl - (2 ®1) D-fructose, a product of the enzymic hidrolysis of the inulin from Chicorium intyhis. Carbohydrate Res., 1992.

DAVIDSON, M. et al. Effects of dietary inulin on serum lipids in men and women with hyper cholesterolemia. Nutr. Res., v.18, n.3, p.503-517, 1998.

DE LEENHEER, L.; HOEBREGS, H. Progress in the elucidation of the composition of chicory inulin. Starch, v.46, p.193, 1994.

DELZENNE, N. et al. Effect of fermentable fructooligosaccharides on mineral, nitrogen and energy digestive balance in the rat. Life Sci., v.57, p.1579-1587, 1995.

DELZENNE, N. et al. Dietary fructo-oligosaccharides modify lipid metabolism in rats. Am.J. Clin. Nutr., v.57, suppl., p.820S, 1993. 
ELLEGARD, L.; ANDERSON, H.; BOSAEUS, I. Inulin and oligofructose do not influence the absorption of cholesterol, and the excretion of cholesterol,Fe, $\mathrm{Ca}, \mathrm{Mg}$, and bile acids but increase energy excretion in man. A blinded, controlled cross-over study in ileostomy subjects. Eur. Clin. Nutr., v.51, p.1-5, 1997.

FIALA, V.; JOLIVET, E. Variations quantitatives en composés azotes et glucidiques de raciness d'asperges, mâles et femelles, au cours de leur première année de culture. Agronomie, v. 2, p.735-740, 1982.

FIORDALISO, M.. et al. Dietary oligofructose lowers triglycerides, phopholipids and cholesterol in serum and very low density lipoproteins in rats. Lipids, v.30, p.163$167,1995$.

FONTANA, J. D. et al. PCR protocol and inulin catabolism based differentiation of inulinolytic soil bactéria. Appl. Biochem. Biotechol., v.45/46, p.269-282, 1994a.

FONTANA, J. D. et al. Microbial inulinase secretion using chemically modified inulins. Appl. Biochem. Biotechnol., v.45/46, p.257-268, $1994 \mathrm{~b}$.

FULLER, R. (Ed.). Probiotics 2: applications and practical aspects. London: Chapman \& Hall, 1997.

FULLER, R. (Ed.). Probiotics: the scientific basis . London: Chapman \& Hall, 1992.

FULLER, R. Probiotics in man and animals. J. Appl. Bacteriol., v.66, p.365-378, 1989.

GAMET, L. et al. Effects of short-chain fatty acids or growth and differentiation of the human colon cancer all line HT29. Int. J. Cancer, v.52, p.286-289, 1992.

GIBSON, G. R.; MACFARLANE, G. T. (Eds.) Human colonic bacteria. Role in physiology, pathology and nutrition. Boca Raton: CRC Press, 1995.

GIBSON, G. R.; ROBERFROID, M. B. Dietary modulation of the human colonic microbiota-introducing the concept of prebiotics. J. Nutr., v.125, p.1401-1412, 1995.

GIBSON, G. R.; WANG, X. Enhancement of bifidobacteria from human get contents by oligofructose using continuous culture. FEMS Microbiol. Lett., v.118, p.121-128, 1994.

GIBSON, G. R. Dietary modulation of the human gut microflora using the prebiotics oligofructose and inulin. J. Nutr., v.129, suppl., p.1438-1441, 1999.

GIBSON, G. R. et al. Selective stimulation of bifidobacteria in the human colon by oligofructose and inulin. Gastroenterology, v.108, p.975-982, 1995.
GRAHAM, H.; ANAN, P. Composition and digestion in the pig gastrointestinal tract of Jerusalem artichocke tubers. Food Chem., v.22, p.67-76, 1986.

GRUHN, E. Inulin-dietary fiber from chicory and fructose syrups processed thereof. Food Process., v.6. p.7, 1994.

HATA, Y. et al. The effect of fructo-oligosaccharides (Neosugar) on lipidemia. Geriatr. Med., v.21, p.156-167, 1983.

HAULY, M. C. O. Inulina de dália: extração e avaliação da hidrólise e dos efeitos biológicos do subprodutos. 1991.185p. Tese (Doutorado em Ciências) - Universidade Federal do Paraná, Curitiba.

HAULY, M. C. O.; BRACHT, A.; BECK, R.; FONTANA, J. D. Fructose and fructoseanhydrides from Dahlia inulin. Appl. Biochem. Biotechol. 34/35, p. 297-308, 1992.

HIDAKA, H.; EIDA, T.; TAKIZAWA, T.; TOKUNAGA, T. \& TASHIRO, Y. Effects of fructo-oligosaccharides on intestinal flora and human health. Bifidobacteria Microflora 5, p. 37-50, 1986.

HOEBREGS, H. Fructans in foods and food products, ion-exchange chromatographic method: collaborative study. J. Assoc. Off. Anal. Chem. Int., 80, p.1029-1037, 1997.

HUGHES, R.; ROWLAND, I. R. Stimulation of apoptosis by two prebiotic chicory fructans in the rat colon. Carcinogenesis, v.22, n.1, p. 43-47, 2001.

ISOLAURI, E. et al. human Lactobacillus strain (Lactobacillus casei sp. strain GG) promotes recovery from acute diarrhea in children. Pediatrics, v. 88, p.9097, 1991.

IUB-IUPAC. Joint Comission on biochemical nomenclature and abbreviated terminology of oligosaccharide chains recommendations 1980. J. Biol. Chem., v.257, p.334, 1982.

KARPPINEN, S. et al. In vitro fermetation of polysaccharides of rye, wheat and oat brans and inulin by human faecal bacteria. J. Scie. Food Agric., v.80, p.1469-1476, 2000.

KLEESEN, B. et al. Effects of inulin and lactose on fecal microflora, microbial activity, and bowel habit in elderly constipaded persons. Am. J. Nutr., v.65, p.1397-1402, 1997.

KNUDSEN, K. E. B.; HESSOV, I. Recovery of inulin from Jerusalem artichoke (Helianthus tuberosus L.) in the small intestine of man. Br. J. Nutr., v.74, p.101-113, 1995.

KOHWI, Y. et al. Antitumor effect of Bifidobacterium infantis in mice. Gann. v.69, p.613-618, 1978. 
$\mathrm{KOK}, \mathrm{N}$. et al. Involvement of lipogenesis in the lower VLDL secretion induced by oligofructose in rats. J. Nutr. 126, p. 881-890, 1996.

KOLBYE, A. C. et al. Evaluation of the food safety aspects of inulin and oligofructose. GRAS Determination Orafti Internal Report, Orafti, Tienen, Belgium, 1992.

KULKARNI, N.; REDDY, B. S. Inhibitory effect of bididobacterium longum cultures on the azoxymethane - induced aberrant crypt foci formation and fecalbacterial b-glucuronidase. Proc. Soc. Exp. Biol. Med., v.207, p.278283, 1994

LEE, S.; PROSKY, L. International survey on dietary fiber: definition, analysis and reference material. J. AOAC intl., v.78, n.1, p.22-36, 1995.

LEVRAT, M. A.; RÉNÉSY, C.; DEMIIGNÉ, C. High propionic fermentation and mineral accumulation in the cecum of rats adapted to different levels of inulin. J. Nutr., v.121, p.1730-1737, 1991.

LIN, S. Y. et al. Lactobacillus effects on cholesterol: in vitro and in vivo results. J. Dairy Sci., v.72, p.2885-2889, 1989.

LOPEZ, H. W. et al. Fructooligosaccharides enhance mineral apparent absorption and counteract the deleterius effects of phytic acid on mineral homeostasis in rats. $J$. Nutr. Biochem., v.11, p.500-508, 2000.

MANSON, J. E. et al. Body weight and mortality among women. N. Engl. J. Med., v.333, p.677-685, 1995.

MENNE, E. et al. Prebiotic effect of the (fructosylfructose) $\mathrm{F}_{\mathrm{m}}$ - type inulin hidrolysate in humans. In: NDO SYMPOSIUM, 1997, The Netherlands, Wageninger. Book of Abstracts... The Netherlands, 1997. p.164.

MILNER, J. A. Reducing the risk of cancer. In: GOLDBERG, T. (Ed.). Functional Foods. London: Chapman \& Hall, 1994. p.39-70

NILSSON, U.; DAHLQUIST, A. Cereal fructosans characterization and structure of wheat fructans. Food Chem., v.22, p.95-106, 1986.

NILSSON, U. et al. Cereal fructans: in vitro and in vivo studies on availability in rats and humans. J. Nutr., v.119, p.1325-1330, 1988.

NINESS, K. R. Inulin and oligofructose: what are they? J. Nutr., v.129, suppl., p.1402-1406, 1999.

OHTA, A.. Dietary fructooligosaccharides present osteopenia after gastrectomy in rats. J. Nutr., v.128, p.106110, 1998.

OHTA, A. et al. Effects of fructooligosaccharides on the absorption of $\mathrm{Mg}$ e Ca by cectomized rats. Int. Vitam. Nutr. Res., v.64, p.316-323, 1994.
OKEY, R.; WILLIAMS, A. W. On inulin in the globe artichoke. J. Am. Chem. Soc., v.42, p.1693-1696, 1920.

OKU, T.; TOKUNAGA, R. Improvement of metabolism: effect of fructooligosaccharides on rat intestine. In: NEOSUGAR RESEARCH CONFERENCE, 2., 1984, Tokyo. Proceeding... Tokyo, 1984. p.53-65.

PILCH, S.M. Physiological effects and health consequences of dietary fiber. Bethesda : Life Sci.Res.Off., Federation of American Societies for Experimental Biology, 1987.

PRICE, M.; SCWARTZ, R.; HOYT, H. Evaluation and characteristics of currently available inulin. Investing. Urol., v.16, p.13-14, 1978.

QUEMENER, B.; THIBAULT, J. F.; COUSSEMENT, P. Determination of inulin and oligofructose in food products, and integration in the AOAC method for measurement of total dietary fibre. $L W T$, v.27, p.125-132, 1994.

QUEMENER, B.; THIBAULT, J. F.; COUSSEMENT, P. Integration of inulin determination in the AOAC method for measurement of total dietary fiber. Int. J. Biol. Macrom., v.21, p.175-178, 1997.

REDDY, B. S. Possible mechanisms by which pro-and prebiotics influence colon carcinogenesis and tumor growth. Found of Nutrition, v.129, Suppl., p.14785-14725, 1999.

RIMM, E. B. et al. Dietary fiber, inulin and oligofructose: a review comparing their physiologycal effects. Crit. Rev. Food Sci. Nutr., v.33, n.2, p.103-148, 1993.

ROBERFROID, M. B. Dietary modulation of experimental neoplastic development: role of fat and fibre content and caloric intake. Mutat. Res., v.259, p.351-362, 1991.

ROBERFROID, M. B.; VAN LOO, J.; GIBSON, G. R. The bifidogenic nature of chicory inulin and its hydrolysis products. J. Nutr., n.128, p.11-19, 1998.

ROLAND, N. et al. Comparative study of the fermentative characteristics of inulin and different types of fiber in rats inoculated with a human wlhole fecal flora. Br. J. Nutr., v.74, n.2, p.239-249, 1995.

ROLAND, N. et al. Hepatic and intestinal cytocrone $\mathrm{P} 450$, glutathion-S-transferases and UDP-glicurenyltransferase are affected by six types of dietary fibre in rats inoculated with human whole fecal flora. J. Nutr., v.124, n.9, p.1581-1587, 1994b.

ROLAND, N. et al. Influence of dietary fibres on two intestinal transferases in rats inoculated with a whole human fecal flora. R. Soc. Chem., v.123, p.369-373, 1994a. 
ROLAND, N. et al. Modulation of the biogenical effects of glucosinalates by inulin and oat fibre in gnotobiotic rats inoculated with a whole human flora. Food and Chem. Toxicology, v.34, p.671-677, 1996.

RUTHERFORD, P. P.; WHITTLE, R. The carbohydrate composition of onions during long term cold storage. $J$. Hortic. Sci., v.57, p.349-356, 1982.

SÁ, R. M.. de; FRANCISCO, A de. Fibras alimentares: curso teórico-prático. Florianópolis: Univ. Federal Santa Catarina. 1999. Apostila do CERES.

SANDERS, M. E Lactic acid bacteria as promoter of human health. In: GOLDEBERG, T. (Ed.). Functional Foods: Designer Foods, Pharmafoods and Nutraceuticals. London: Chapman \& Hall, 1994. p.294-322.

SANNO, T. Effects of Neosugar on constipation, intestinal microflora and gollbader contraction in diabetics. In: NEOSUGAR RESEARCH CONFERENCE, 3., 1986, Tokyo. Proceeding... Tokio, 1986.

SILVA, R. F. Use of inulin as a natural texture modifier. Cereal Foods World, v.41, n.10, p.792-794, 1996.

SIMONOVSKA, B. Determination of inulin in foods. $J$. AOAC Int., v.83, n.3, p.675-678, 2000.

SUZUKI, M.; CUTCLIFE, J. A. Fructan in onion bulbs in relation to storage life. Can. J. Plant Sci., v.69, p.13271333, 1989.

TAGUCHI, A. et al. The influence of fructooligosaccharides on the bone of model rats with ovarectomized osteoporosis. Sci. Rep. Meiji Seika Kaisha, v.33, p.37-44, 1994.

TAPER, H. S.; ROBERFROID, M. B. Influence of inulin and oligofructose on breast cancer and tumor growth. $J$. Nutr., v.129, Suppl., p.1488-1491, 1999.

TROWEL, H.; BURKITT, D. Physiological role of dietary fiber: a ten years review. J. Dent. Child., v.53, p.444-447, 1986.

TROWEL, H. Ischemic heart disease and dietary fiber. Am. J. Clin. Nutr., v.25, p.926-932, 1972.

VAN DEN HEUVEL, E.; MUYS, T. VAN DOKKUN, W. \& SCHAFSMA, G. Oligofructose stimulates calcium absorption in adolescents. Am. J. Clin. Nutr. 69, p. 544548, 1999.
VAN DEN HEUVEL, E. et al. Nondigestible oligosaccharides do not interfere with calcium and non heme iron absorption in young, health men. Am. J. Clin. Nutr., v.67, p.445-451, 1998.

VAN HAASTRECHT, J. Promising performers; oligosaccharides present new product development opportunities for wide range of processed foods. Int. Food Ingredients, n.1, p.23-27, 1995.

VAN LOO, J. et al. Inulin and oligofructose in the western diet. (in press). Crit. Rev. Food Sci. Nutri., v.35, n.6, p.525$552,1995$.

VAN LOO, J. et al. Functional food properties of nondigestible oligosaccharides: concensus report from ENDO project. Br. J. Nutr., v.81, p.121-132, 1999.

VAN REE, L. Niewws rond de teel van groenten. B. Industriegroenten - 5: waar staan we net de teelt van schorseneer. Landbouwtydschrift, v.3, p.2361-2364, 1982.

VORAGEN, A. G. J. Technological aspects of functional food-related carbohydrates. Trends Food Sci. \& Techn., v.9, p.328-335, 1998.

WANG, X.; GIBSON, G. R. Effects of the in vitro fermentation of oligofructose and inulin by bacteria growing in the human large intestine. J. Appl. Bacteriol., v.75, p.373-380, 1993.

WEIDMANN, M.; JAGER, M. Synergistic sweetners. Food Ingredients Int., p.51-56, nov-dez., 1997.

WILLIAMS, C. H. Effects of inulin lipid parameters in humans. J. Nutr., v.129, p.1471-1473, 1999.

WILLIAMS, C. M.; DICKERSON, J. W. Nutrition and cancer. Some biochemical mechanisms. Nutr. Res. Rev., v.3, p.45-100, 1990.

WRIGHT, R. S.; ANDERSON, J. W.; BRIDGES, S. R. Propionate inhibits hepatocyte lipid synthesis. Proc. Soc. Exp. Biol. Med., v.195, p.26-29, 1990.

YAMASHITA, K.; KANAI, K.; ITAKURA, M. Effects of fructo-oligosaccharides on blood glucose and serum lipids in diabetic subjects. Nutr. Res., v.4, p.961-966, 1984.

ZIESENITZ, S. C.; SIEBERT, G. The metabolism and utilization of polyols and other bulk sweeteners compared with sugar. Developments in Sweeteners - 3. Elsevier applied science, 1987. 